\title{
Study of outcomes of metaphyseal plate fixation in extra articular lower tibia fractures in adults
}

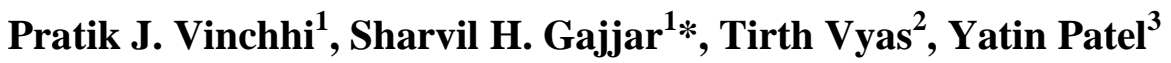

Department of Orthopaedics, ${ }^{1}$ GCS Medical College and Hospital, Ahmedabad, Gujarat, ${ }^{2}$ Port Trust hospital Mumbai, Maharashtra, ${ }^{3}$ Government Medical College, Surat, Gujarat, India

Received: 20 March 2017

Revised: 21 April 2017

Accepted: 07 April 2017

*Correspondence:

Dr. Sharvil H. Gajjar,

E-mail: sharvilgajjar@yahoo.co.in

Copyright: () the author(s), publisher and licensee Medip Academy. This is an open-access article distributed under the terms of the Creative Commons Attribution Non-Commercial License, which permits unrestricted non-commercial use, distribution, and reproduction in any medium, provided the original work is properly cited.

\begin{abstract}
Background: The purpose of the present study was to see results of metaphyseal plate fixation in fractures of distal tibia in adults.

Methods: This is a retrospective study of 45 patients with 45 open fractures of tibia operated primarily by either Solid Titanium or Stainless steel tibia interlocking nail within 24 hours of injury.

Results: In Our Study we had studied 30 lower tibial fractures treated by precontoured metaphyseal anatomical plate. $24(80 \%)$ patients were male. 19 patients were 20-45 years age group. Mean age was 34 years. 24(80\%) fractures were due to Road traffic accidents. We had $26(86 \%)$ patients with closed fracture and 4(14\%) patients with open fracture. Average time of surgery in our series was 52 minutes. 6(20\%) patients had infection. And 2(6.67\%) patients had nonunion and both were due to infection and required implant removal and conversion to external fixation. Average time for fracture union was 18 months. In our study of 30 patients 23(76.67\%) patients had good to excellent results as assessed by AOFAS score.

Conclusions: From this study we can conclude that when properly indicated the use of anatomically precontoured medial tibial metaphyseal plate in treatment of distal tibia fractures gives good union and good functional result.
\end{abstract}

Keywords: Extra articular distal tibia fracture, Anatomical metaphyseal plate, AOFAS score

\section{INTRODUCTION}

Distal tibial fractures are one of the most complex injuries involving the ankle joint, accounting for approximately $7 \%$ of all tibial fractures. ${ }^{1}$ Conventionally the treatment of these fractures is considered to be a challenging task because of less soft tissue coverage over the bone, comminution of weight bearing articular surface of distal tibia, high chances of nounion (5-6.6\%), open injuries more common, difficulties in reduction and internal fixation and less availability of low profile implants, which devitalizes the bone fragments and surrounding soft tissue. ${ }^{2}$
To add to this problem, modern lifestyle and increase in high speed road traffic accidents especially two wheelers has lead to an increased incidence of complex fractures of the distal tibia which has made their treatment all the more difficult.

But considerable advances have been made in the method of internal fixation and various new operative techniques have helped us to meet such difficulties better. Some such advances are 


\section{Innovation in implants}

Plates: Availability of Anatomical precontoured plates, availability of low profile plate, LCP combination hole with undercuts, optimal distal application of head screw and guiding blocks

\section{Advances in operative techniques like}

MIPO (minimally invasive plate osteosynthesis) technique of insertion, biological i.e. preservation of soft tissue given more importance to anatomy. ${ }^{3,4}$ Bridge plating is becoming more popular.

All these has improved the bony fixation, and preserved the vascularity and surrounding soft tissue and improved the result.

One such implant used in the treatment for distal tibial fractures are the anatomical precontoured metaphyseal plates which is low profile and literature claims it to be giving good results. 5,6

In this study an attempt has been made to evaluate the results of metaphyseal plating for distal tibia in terms of duration of treatment, union time and ultimate functional outcome.

\section{METHODS}

We have done a retrospective study of 30 fractures of lower end of tibia treated by anatomically contoured lower tibial metaphyseal plate at GCS medical college and hospital from May 2015 to December 2016 and they were followed up at regular interval with follow up of minimum 6 months.

\section{Selection criteria}

\section{Inclusion criteria}

Inclusion criteria were patient above 18 years, all closed fractures, open fractures grade 1 and Grade 2 of Gustilo and Anderson classification.

\section{Exclusion criteria}

Exclusion criteria were patient $<18$ years, Gustillo and Anderson classification grade 3 open fracture, associated vascular injury or compartment syndrome, pathological fractures.

\section{Preoperative preparation and assessment}

The patients were received in trauma ward. On admission, patient was first examined thoroughly in Primary survey for vital data and other major associated injuries in head, thorax, abdomen or spine along with local appendicular injuries.

\section{Primary management}

Admit in trauma ward with above knee slab with bohler elevation. The wounds, if any, were washed with $\mathrm{H}_{2} \mathrm{O}_{2}$ betadine and then saline under aseptic precautions and sterile dressing kept. Intravenous antibiotics in case of open wounds. Injection Tetanus toxoid as and when needed. Intravenous analgesics. After primary assessment and stabilization of patient we prepare the patient for the surgery:

\section{Fracture assessment}

Each fracture is classified by using $\mathrm{AO}$ fracture classification system. .

\section{Implants available}

Plates

Different variations are available as anatomically contoured plate, dynamic compression plate, low contactdynamic compression plate, locking compression plate and reconstruction plate

\section{External fixator}

They can be conventional, hybrid fixator, Ilizarov, fixator plus ORIF minimal invasive and articular reconstruction.

If the patient falls into the inclusion criteria, we treat the patient by anatomically contoured metaphyseal plate.

Definitive management and surgical technique for distal tibia plating

Patient is operated under spinal anaesthesia/general anaesthesia. Patient is positioned supine on radiolucent table. Antibiotic prophylaxis is administered. Standard intraoperative fluoroscopy is used throughout the procedure. Great care should be taken to ensure that the fracture can be clearly visualized on anteroposterior and lateral views.

\section{AO ASIF principles for internal fixation were strictly adhered to ${ }^{7,8}$}

1) Anatomical reduction

2) Stable fixation

3) Preservation of blood supply

4) Early mobilization

\section{Postoperative protocol}

Antibiotics like injection Ceftriaxone $1 \mathrm{gm}$ intravenous for every 12 hourls was continued for first 3 days and 
then it was shifted to oral. Suction drainage was removed after 48 hours in case of open reduction. Intravenous analgesics were given for 1 day followed by oral analgesics when necessary.

\section{Hospital stay}

Patient is discharged as soon as the wound and general condition of the patient is satisfactory, usually around postoperative day 6. Sutures were removed on 12th postoperative day. Patients were advised to walk non weight bearing walking (NWBW) after suture removal. Ankle movements were allowed after 3 weeks. Partial weight bearing walking (PWBW) to full weight bearing was started once further collapse is not expected radiologically i.e. usually around 12 weeks. Initially full weight bearing is allowed with support like crutches or walker and then gradually without support. Radiologically fracture is considered to be united, when visible bridging callus is seen in at least three cortices in anteroposterior and lateral view. Clinically fracture is considered to be united, when patient is completely pain free on bearing weight. ${ }^{\text {' }}$

\section{Follow up}

Patient is asked to come for follow up at 12 to 15 days for stitch removal and then at 1,2, 3 and 6 months and then at 1 year from the date of surgery for final follow up. At each follow up patient is assessed clinically and radiologically.

\section{RESULTS}

Total 30 patients were included in the study, amongst them $80 \%$ are males. The Youngest patient in the series is 20 years old. $19(63 \%)$ patients belongs to the age group of 18 to 45 years, of these 19 patients, 15 are males.

$80 \%$ of patients sustained injuries due to road traffic accidents and $6(20 \%)$ patients were having other modes of injury like assault, fall, and fall of heavy objects.

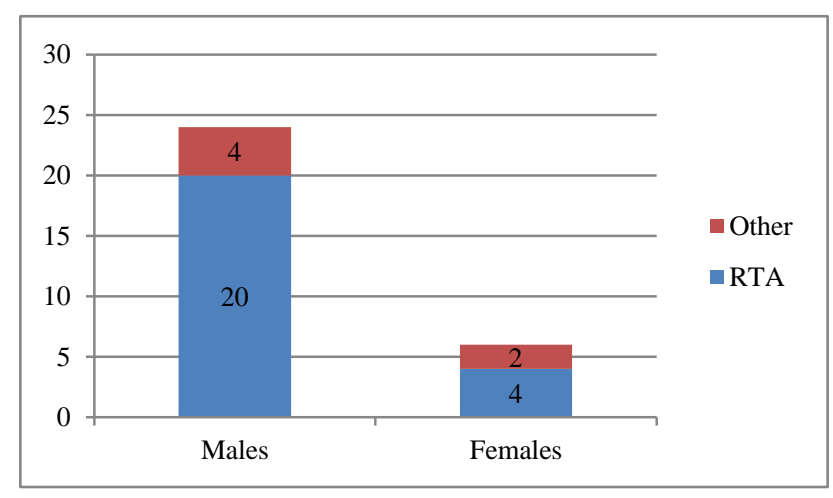

Figure 1: Mode of injury.

Fractures were more frequent on right side of tibia i.e. 18 (60\%) patients. $11(35 \%)$ patients had comminuted intraarticular fractures and $8(27 \%)$ patients had extra articular comminuted fractures. In our series 9(30\%) patients have other bony injuries along with the tibia fracture. Most of the lower end tibia fractures were associated with fracture of the fibula except five. In polytrauma cases and such communited fractures, MIPO technique is useful to prevent blood loss and reduce operative time.

In our series $26(86 \%)$ patients have closed fracture and 4 (14\%) patients have open fracture, according to the Gustilo Anderson (type 1 and 2). Though there was open injury in only $4(14 \%)$ patients, there was an element of soft tissue injury (blunt) in most of the patients.

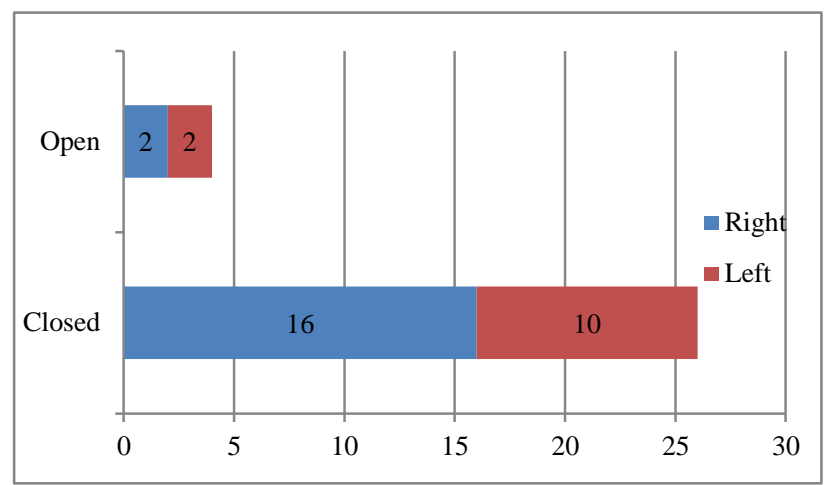

Figure 2: Fracture grade and side.

Average time interval between injury and operation in our study is 1.8 day. 8 (26\%) patients were given blood transfusion. $6(20 \%)$ patients had co morbid conditions which required blood transfusion and other 2 had polytrauma in which blood transfusion was needed to treat hypovolemic shock.

Average time of surgery in our series was 52 minutes. The average duration of hospital stay in our study is 8 days. On an average it is 5 to 6 days of hospitalization but in one patient the stay was 42 days due to co morbid conditions (polytrauma) which has lead to increase the average stay to 8 days. In our series 28 (93\%) patients had union of the fracture.

The average union time in our study is 18 weeks. In our study $2(6.66 \%)$ patients delayed union/nonunion.

In present study $10(33.33 \%)$ patients had developed complications such as infection, stiffness, Implant exposed or breakage, delayed or nonunion. 4 patients had superficial infection and were managed by regular dressings and higher antibiotics, while 2 had deep infection, necessitating implant removal and conversion to external fixator.

$23(77 \%)$ patients in our series have good to excellent results as assessed by AOFAS SCORE (American orthopaedic foot and ankle society ankle score) Though we had no reservation for open reduction in this series of 
30 patients no patient required open reduction and all the patients were treated by MIPO technique of plate fixation. Thus the series may be considered a follow up of patients treated by MIPO.

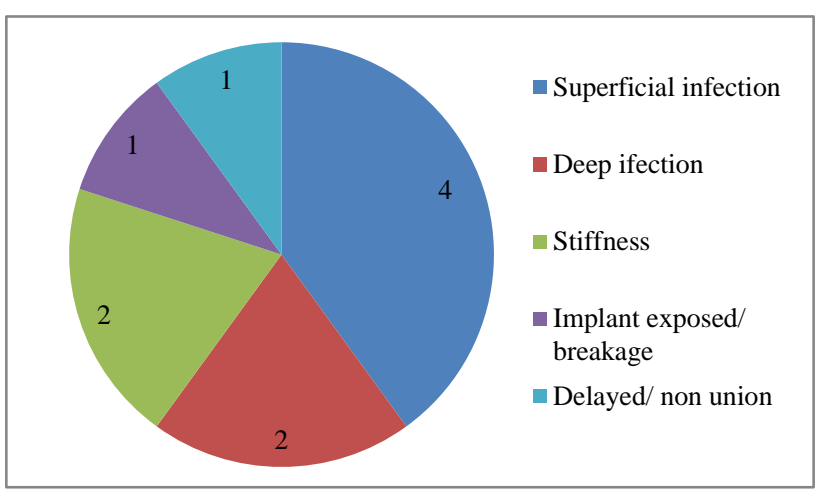

Figure 3: Complications.

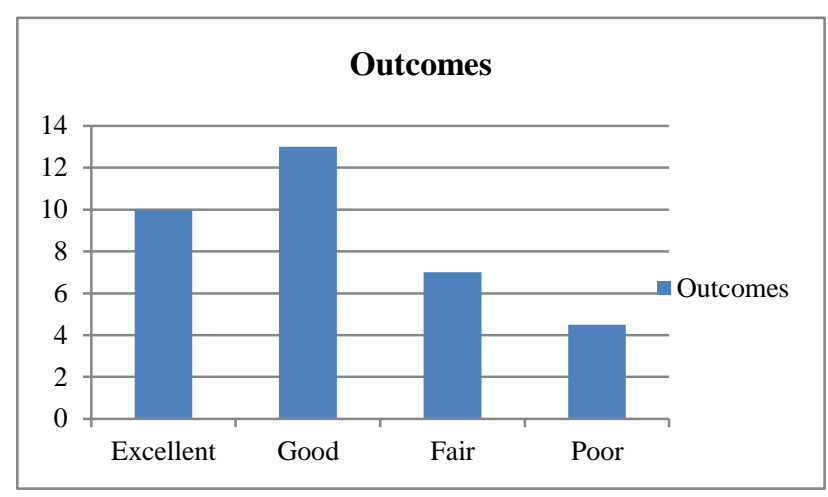

Figure 4: Outcomes AOFAS score.

\section{DISCUSSION}

Total 30 patients were included in the study, amongst them $80 \%$ are males. $19(63 \%)$ patients belongs to the age group of 18 to 45 years, of these 19 patients, 15 are males. This may be because, in the Indian society males are more active and thus there are higher chances of accidents and other injuries.

$80 \%$ of patients sustained injuries due to road traffic accidents and $6(20 \%)$ patients were having other modes of injury like assault, fall, and fall of heavy objects. These $80 \%$ of patients in this series have high velocity trauma resulting from vehicular accidents, leading to greater degree of soft tissue and bony injury. Thus nearly $60 \%$ patients in our series had comminution at fracture site, which can be attributed to high velocity trauma.

The average union time in our study is 18 weeks. This is comparable to studies by Collinge et al (21 weeks) and Im et al (20 weeks) with MIPO and ORIF method. ${ }^{5,11}$ In our study $2(6.66 \%)$ patients delayed union/nonunion. which is also comparable with other studies by Collinge et al $(7 \%)$ and Im GI et al $(8 \%))^{5,11}$
In studies by Anglenet al with Hybrid fixator technique $42 \%$ patients and Joveniaux et al with ORIF technique $29 \%$ patients had developed complications. ${ }^{2,12}$ Where as in study by Collinge et al with MIPO technique $18 \%$ patients had developed complications such as Implant exposed/breakage, delayed/nonunion, malalignment. ${ }^{11}$ In present study $10(33.33 \%)$ patients had developed complications such as infection, stiffness, Implant exposed or breakage, delayed or nonunion. This is slightly more as compared to the MIPO series that we have compared. This is because we have encountered 6 (20\%) infections whereas this series has no infection. 4 patients had superficial infection and were managed by regular dressings and higher antibiotics, while 2 had deep infection, necessitating implant removal and conversion to external fixator. In our series the infection rate could be more because of infrastructure problems and the poor immunity status of the patients, but never the less these complications have not disturbed the activities of daily living of these patients.

$23(77 \%)$ patients in our series have good to excellent results as assessed by AOFAS SCORE (American orthopaedic foot and ankle society ankle score) which is comparable to Collinge et al, who have $78 \%$ good to excellent results using the MIPO technique for locking compression plate. $^{11}$ Reudi and Allgower had $74 \%$ good to excellent results which are also comparable with our series. $^{13}$

\section{CONCLUSION}

In Our Study we had studied 30 lower tibial fractures treated by precontoured metaphyseal anatomical plate. Assessment by the AOFAS score suggests that $76 \%$ of the patients had good to excellent results when treated with metaphyseal plate with a very low rate of complications that can be attributed to be caused by the implant rather than the fracture type. Thus we conclude that when properly indicated the use of anatomically precontoured medial tibial metaphyseal plate in treatment of distal tibia fractures gives good fracture union and good functional results.

Funding: No funding sources

Conflict of interest: None declared

Ethical approval: The study was approved by the institutional ethics committee

\section{REFERENCES}

1. Rockwood Charles A Jr, Green David P. Rockwood \& Green's Fractures in Adults. Bucholz RW, Heckman JD, Court-Brown CM, editors. Chapter 58. 2014: 2473-2541.

2. Joveniaux P, Ohl X, Harisboure A, Berrichi A, Labatut L, Simon P. Distal tibia fractures: management and complications of 101 cases. Int Orthop. 2010;34(4):583-8. 
3. Baumgaertel F, Buhl M, Rahn BA. Fracture healing in biological plate osteosynthesis. Injury. 1998;29(3):3-6.

4. Im GI, Tae SK. Distal metaphyseal fractures of tibia: a randomized trial of closed reduction and intramedullary nail vs. plate. $\mathrm{J}$ trauma. 2005;59(5):1219-23.

5. Miclau T, Martin RE. The evolution of modern plate osteosynthesis. Injury. 1997;28(1):3-6.

6. Sommer C, Rüedi TP. Tibia distal (pilon). In: Rüedi TP, Murphy WM, editors. AO Principles of Fracture Management. New York, NY: Thieme; 2000: 539544.

7. Müller ME, Allgöwer M, Schneider R, Willenegger H. In: Allgöwer, Martin, editors. Manual of Internal Fixation ED 3; Techniques recommended by AOASIF. Springer Verlag; 1991: 12-23.

8. Vallier HA, Le TT, Bedi A. Radiographic and Clinical Comparisons of Distal Tibia Shaft Fractures (4 to $11 \mathrm{~cm}$ Proximal to the Plafond): Plating Versus Intramedullary nailing. $\mathbf{J}$ Orthop Trauma. 2008;22(5):307-11.
9. Janssen KW, Biert J, Kampen AV. Treatment of distal tibial fractures: plate versus nail. Int Orthop. 2007;31(5):709-14.

10. Yang SW, Tzeng HM, Chou YJ, Teng HP, Liu HH, Wong CY. Treatment of distal tibial metaphyseal fractures: Plating versus shortened intramedullary nailing. Injury. 2006;37(6):531-5.

11. Collinge $C$. Outcome of minimal invasive plate osteosynthesis for metaphyseal distal tibial fracture. J Orthop Trauma. 2010;24:24-9.

12. Anglen, JO. Early Outcome of Hybrid External Fixator for the Fractures of Distal Tibia. J Orthop Trauma. 1999;13(2):92-7.

13. Allgower $R$. The operative treatment of intraarticular fractures of the lower end of tibia. Clinorthop. 1979;138:105-10.

Cite this article as: Vinchhi PJ, Gajjar SH, Vyas T, Patel Y. Study of outcomes of metaphyseal plate fixation in extra articular lower tibia fractures in adults. Int J Res Orthop 2017;3:456-60. 